\title{
Endoscopic local injection of ethanolamine oleate and thrombin as an effective treatment for bleeding duodenal ulcer: a controlled trial
}

\author{
M Moretó, M Zaballa, M-J Suárez, S Ibáñez, E Ojembarrena, J-M Castıllo
}

\begin{abstract}
The injection of a mixture of ethanolamine oleate and thrombin as an effective treatment for bleeding duodenal ulcer was evaluated in 38 patients entered in a randomised prospective controlled trial. After a one week observation period, $1 / 19(5 \cdot 3 \%)$ treated patients and 11/19 $\mathbf{5 7 . 9 \% )}$ control patients had suffered further bleeding ( $p<0.005 ; C I=22 \%-74 \%)$. Emergency surgery was required in $1 / 19$ in the treated group compared with $8 / 19$ in the untreated group $(C I=13 \%-61 \%$; $p<0.05)$. The mean (SD) transfusion requirement in the treated group was $1.9(0.5) \mathrm{U}$ blood compared with 5.3 $(0.7) U$ in the control group. No significant differences related to mortality were detected. In conclusion, local injection therapy is an effective means of haemostasis in patients with bleeding duodenal ulcer who are at risk of further bleeding.
\end{abstract}

Although endoscopy mediated procedures based on thermal therapy (mono- or bipolar electrocoagulation, laser therapy, heater probe) have been considered as successful tools in haemostasis, ${ }^{1}$ technical difficulties have considerably limited their use. Endoscopic haemostasis by means of monopolar electrocoagulation has been shown to be effective but it is a particularly difficult procedure to undertake in the duodenal cap. In a clinical trial, ${ }^{2}$ we were obliged to restrict its use to bleeding gastric ulcer patients. Thus, an alternative endoscopic method for treating duodenal bleeding was required.

Thrombin has been used either topically as a spray $^{3}$ or injected locally, ${ }^{4}$ with seemingly good results. Local injection of several other substances - adrenalin, ${ }^{5}$ polidocanol, ${ }^{6}$ absolute ethanol $^{7}$ - has proved to be as effective in immediate haemostasis in several uncontrolled trials, but controlled trials have been few, ${ }^{89}$ albeit hopeful.

Comparative studies of different injected substances for bleeding peptic ulcers are lacking, so selection depends greatly on subjective views and partly reflects experience with variceal sclerotherapy. Ethanolamine oleate has been extensively used in variceal sclerosis, mainly in Commonwealth countries. However, we have not been able to find any reference to its use as a sclerosant in bleeding gastroduodenal ulcers. Kitano et al found polidocanol responsible for a greater frequency of complications than ethanolamine. ${ }^{10}$ Sodium tetradecyl sulphate has been used experimentally in deep ulcers." Finally, Sarin found absolute ethanol more effective than ethanolamine, with no differences in respect of complications, ${ }^{12}$ although in an experimental study absolute ethanol resulted in more necrosis than polidocanol ${ }^{13}$

We undertook this controlled clinical trial to evaluate the local injection of thrombosclerosants, employing a mixture of a sclerosing agent - ethanolamine oleate - and thrombin as a procoagulant in order to achieve haemostasis in selected patients with bleeding duodenal ulcers. We decided to combine both substances according to our usual practice in variceal sclerotherapy because ethanolamine plus thrombin is more effective than ethanolamine alone as a haemostatic agent in oesophageal varices. ${ }^{1+}$

\section{Methods}

PATIENTS

All patients admitted to hospital with upper gastrointestinal haemorrhage underwent endoscopy as soon as possible, and in every case within 16 hours. Patients with a duodenal ulcer diagnosed as the source of the haemorrhage, in whom active bleeding was present or in whom a non-bleeding vessel was visible, and who had received three or more units of blood at the time of the diagnosis were included in the trial provided that they gave informed consent. According to our endoscopic classification of bleeding ulcer signs (Table I), we included all $I a 1$ patients and some Ia 2 patients. When a clot adhering to the base of the ulcer was found we tried to remove it by means of gentle aspiration. If this was not possible, the patients was not included in the study.

When criteria for inclusion were fulfilled, and if visibility was judged acceptable for thrombosclerosis, a sealed envelope was taken out and

TABLE I Classification and frequencies of bleeding duodenal ulcer, according to endoscopic signs, during the trial

Group 1: Patients with stigmata of bleeding (211 (95.5\%))

\begin{tabular}{|c|c|c|}
\hline $\begin{array}{c}\text { Ia With a visible vessel } \\
(65(29 \cdot 4 \%))\end{array}$ & $\begin{array}{l}\text { Ial Bleeding } \\
\text { vessel }\end{array}$ & $\left\{\begin{array}{l}\text { Spurting } \\
(18(8 \cdot 1 \%)) \\
\text { Oozing } \\
(17(7 \cdot 6 \%))\end{array}\right.$ \\
\hline & $\begin{array}{l}\text { Ia2 Non-bleeding } \\
\text { vessel }(30(13 \cdot 6 \%))\end{array}$ & \\
\hline
\end{tabular}

Ib Base covered by an unremoved clot $(49(22 \cdot 2 \%))$

$$
\begin{gathered}
\text { Ic No visible vessel } \\
(97(43 \cdot 9 \%))
\end{gathered} \quad\left\{\begin{array}{l}
\text { Ic1 Oozing } \\
(13(5 \cdot 9 \%)) \\
\text { Ic2 Non-bleeding } \\
(84(38 \%))
\end{array}\right.
$$

Group II: Patients without stigmata of bleeding (10 (4.5\%)

Total: 221 bleeding episodes 
the patient was assigned to either the thrombosclerosis treatment group or control group.

\section{EXCLUSIONS}

Five patients who seemed to meet the inclusion criteria were excluded before randomisation because excessive blood collection in the duodenum or duodenal deformity, or both, made treatment highly problematic and unsafe for technical reasons. One of them had alcoholic cirrhosis of the liver with suspected untreated hepatocellular carcinoma. Another patient presented in severe respiratory failure and had a pacemaker. (Exceptionally, he was given thrombosclerosis treatment, out of protocol, in very difficult conditions). Both these patients continued to bleed and died a few days later. Two patients had to be operated on because of persistent haemorrhage. The remaining patient followed an uneventful course, and bleeding stopped spontaneously.

Another patient who presented had suffered a cerebral stroke which made him highly uncollaborative. He was excluded from the study and followed an uneventful course.

\section{MONITORING}

An elementary questionnaire, with registration of basic haemodynamic data, was routinely completed at our unit before the endoscopic procedure was carried out. After endoscopy a form was filled in, including clinical and endoscopic data. Both groups of patients were treated by gastroenterologists not related to the trial, who were unaware of the applied therapy. They were only informed about the haemorrhagic activity at the end of the endoscopic procedure. Routine medical treatment included standard doses of $\mathrm{H}_{2}$ antagonists (cimetidine and ranitidine).

Evaluation of the effectiveness of treatment was undertaken over a seven day period and included the following: rebleeding, need for emergency surgery, and transfusion requirements. Rebleeding was defined as an episode of haematemesis or melaena, or both, with signs of shock or confirmative upper endoscopy, or both. Emergency surgery was defined as surgery carried out during the observation period. Transfusion requirements were measured separately for pre- and postendoscopy periods.

To determine whether there was any worsening of the ulcer secondary to sclerosant treatment, a control upper endoscopy was routinely undertaken at the end of the evaluation period in patients treated with thrombosclerosis.

\section{ENDOSCOPIC TECHNIQUE}

Thrombosclerosis of bleeding ulcers was carried out by gastroenterologists who specialised in endoscopy. An initial dose of $5 \mathrm{ml}$ of $5 \%$ ethanolamine oleate (Evans, UK) and $50 \mathrm{U}$ of bovine thrombin diluted in $5 \mathrm{ml}$ of $50 \%$ hypertonic glucose was selected. Some $1 \mathrm{ml}$ of each (firstly ethanolamine, then thrombin) was injected alternatively in four to five spots around the vessel and then on the vessel itself. If the haemorrhage did not stop, a further dose of sclerosant was administered. Patients were given a mean of $7 \cdot 7 \mathrm{ml}$ (range $4-15 \mathrm{ml}$ ) of ethanolamine oleate.

\section{STATISTICAL METHOD}

The non-paired Wilcoxon test was used to analyse quantitative data. $\chi^{2}$ analysis was used to assess categorical variables, employing Yates's correction or Fisher's exact test where appropriate. Confidence intervals for rebleeding analysis were determined by computer following the method proposed by R Simon. ${ }^{15}$

Because the presumed index of recurrence for patients with a visible vessel is not known, the expectancy varied widely, between $0 \%$ and $81 \%$, the mean being $43 \% .{ }^{16}$ Moreover, our study included an added clinical feature - the preendoscopy blood requirements - which makes it harder to plan the sample size. Consequently, we began by including 38 patients in a pilot study. Then, the expectancy of a type I error was less than $0 \cdot 01$. With the very positive results obtained, our trial was big enough to detect a $50 \%$ relative risk reduction related to recurrence so we decided to end the trial on ethical grounds.

\section{Results}

There were 19 patients in each one of the two groups. There were no significant differences between the groups (Table II) in terms of age, sex, ulcer size (this parameter could be adequately registered in 17 thrombosclerosis patients and in 15 of control group), time elapsed since the apparent beginning of the haemorrhage, arterial pressure, and units of blood given at endoscopy. Nor were significant differences seen in comparing haemorrhagic activity, although there was a trend towards more active bleeding in the thrombosclerosis group.

Significantly more control patients continued to bleed $(11,57.9 \%)$ than thrombosclerosis patients $(15.3 \%) \quad(\mathrm{p}<0.005, \quad \mathrm{CI}=29 \%-77 \%)$ (Table III). Eight control group patients who rebled had to undergo emergency surgery $v$ only one thrombosclerosis patient $(\mathrm{p}<0.05, \mathrm{CI}: 13-$ $61 \%$ ). Postendoscopy transfusion requirements were also different: thrombosclerosis patients required a mean of $1.9(0.5) \mathrm{U}$ compared with 5.3

TABLE II Clinical details of the two groups of patients

\begin{tabular}{|c|c|c|}
\hline & $\begin{array}{l}\text { Thrombosclerosis } \\
\text { group } \\
(n=19)\end{array}$ & $\begin{array}{l}\text { Control } \\
\text { group } \\
(n=19)\end{array}$ \\
\hline Age (mean (SD) ) (yrs) & $54 \cdot 1(21)$ & $57 \cdot 3(21)$ \\
\hline $\operatorname{Sex}(M / F)$ & $19 / 0$ & $16 / 3$ \\
\hline Ulcer size $($ mean $(\mathrm{SD}))(\mathrm{mm})$ & $9 \cdot 4(7)$ & $10 \cdot 5(5)$ \\
\hline Hours elapsed before endoscopy & $30 \cdot 3(25)$ & $51.9(37)$ \\
\hline $\begin{array}{l}\text { Systolic blood pressure (mean } \\
\text { (SD)) (mm Hg) }\end{array}$ & $129(22)$ & $122 \cdot 9(34)$ \\
\hline Blood required (mean $(\mathrm{SD})$ ) (U) & $2 \cdot 1(2)$ & $2 \cdot 7(2)$ \\
\hline \multicolumn{3}{|l|}{ Haemorrhagic activity } \\
\hline \multicolumn{3}{|l|}{$\begin{array}{l}\text { Visible vessel: } \\
\text { P }\end{array}$} \\
\hline Spurting & 10 & 6 \\
\hline Oozing & 8 & 8 \\
\hline Non-bleeding & 1 & 5 \\
\hline \multicolumn{3}{|l|}{ Associated diseases: } \\
\hline Ischaemic cardiopathy & 1 & 2 \\
\hline Liver cirrhosis & i & $\vec{l}$ \\
\hline Neoplastic disease & l & i \\
\hline Renal transplantation & 1 & 0 \\
\hline Diabetes & 1 & 2 \\
\hline Respiratory failure & 1 & 2 \\
\hline
\end{tabular}


TABLE III Analysis of results

\begin{tabular}{llll}
\hline & $\begin{array}{l}\text { Thrombosclerosis } \\
\text { group } \\
(n=19)\end{array}$ & $\begin{array}{l}\text { Control } \\
\text { group } \\
(n=19)\end{array}$ & $\begin{array}{l}p \\
\text { value }\end{array}$ \\
\hline Rebleeding & $1(5 \cdot 3 \%)$ & $11(57 \cdot 9 \%)$ & $\mathrm{p}<0 \cdot 005$ \\
Surgery required & $1(5 \cdot 3 \%)$ & $8(42 \cdot 1 \%)$ & $\mathrm{p}<0 \cdot 05$ \\
Blood requirements & $1 \cdot 9(0 \cdot 5)$ & $5 \cdot 3(0 \cdot 7)$ & $\mathrm{p}<0 \cdot 002$ \\
Deaths & 0 & 2 & $\mathrm{NS}$ \\
\hline
\end{tabular}

$(0.7) \mathrm{U}$ in control patients $(\mathrm{p}<0.002)$.

Two control group patients died, both of them having failed to achieve haemostasis. One was a drug addict who suffered from seminoma and chronic hepatitis $B$. The other one suffered from advanced cirrhosis of the liver. No deaths were registered in the thrombosclerosis group $(\mathrm{p}>0.05)$.

\section{COMPLICATIONS}

No serious complications occurred in the trial Epigastric pain was not induced by the application of thrombosclerosis, nor was it evident during the observation period. The control upper endoscopy undertaken on the seventh day did not show any increase in ulcer width or depth, with the exception of one of the thrombosclerosis patients who experienced a $5 \mathrm{~mm}$ increase in ulcer size.

\section{Discussion}

Mortality secondary to a bleeding duodenal ulcer is considered to be around $12 \%$. About $30 \%$ of these patients will need some $5 \mathrm{U}$ of blood during their hospital stay. When emergency surgery is indicated, mortality increases threefold in respect of patients who are not operated on, ${ }^{18}$ and this justifies the search for a therapeutic endoscopic procedure to meet these patients' needs.

Our results suggest that thrombosclerosis is effective as emergency treatment for duodenal bleeding ulcer in patients selected according to the criteria we have outlined. We did not take into account the later clinical course of these patients because several subsequent treatments were prescribed, including surgery, which would have introduced bias to our analysis.

The effectiveness of local injection of a peptic bleeding ulcer is generally accepted, but there is no agreement over the proposed mechanism of its action. Some variables, such as ulcer size and site, have been proposed as influencing the effectiveness of the procedure. ${ }^{19}$ Some authors have suggested that this treatment works through the compressive action of fluid deposits around bleeding vessel, ${ }^{4}$ while others state that action on vascular endothelium with subsequent thrombosis and necrosis are the natural haemostatic course. ${ }^{13}$ The diversity of injected agents adds to the confusion over the therapeutic mechanism of local injection, particularly since studies comparing administered substances are lacking. In some studies patients were treated with adrenaline, with apparently good results, despite the lack of any known inflammatory or coagulative action of this substance on bleeding vessels. ${ }^{1320}$ In others a mixture of adrenaline and hypertonic saline, adrenaline and polidocanol, ${ }^{7922}$ or isolated poli- docanol were used. ${ }^{+}$Absolute ethanol is becoming one of the most common agents, with an apparent success rate of more than $90 \% .{ }^{23}$ Some authors have added local injection to other haemostatic methods such as laser ${ }^{2+25}$ or monopolar electrocoagulation. ${ }^{26}$ According to a study on the course of ulcer bleeding, ${ }^{27}$ a transverse vessel should be found at the ulcer base showing arteritis and pseudoaneurysmatic changes. It has been suggested that ethanol and sodium tetradecyl sulphate act by inflammatory mediated protracted coagulation, ${ }^{20}$ but this does seem to be the most likely explanation of the haemostatic effect. Added thrombin could potentiate the haemostatic effect of inflammatory substances. In considering the effect of adrenaline in haemostasis, the facts that spontaneous haemostasis occurs with a variable frequency in all series dealing with a bleeding peptic ulcer and visible vessel, including our own experience, ${ }^{2}$ and that adrenaline plus polidocanol are more effective than adrenaline alone ${ }^{28}$ should be taken into account. It is hard to believe that simple transitory vasoconstrictive agents or mechanical compression could, by themselves, achieve definitive haemostasis when severe disruption of the vessel integrity has occurred.

The requirement for blood transfusion as one of our inclusion criteria is based on reported data according to which transfused blood is directly related to emergency surgery needs. ${ }^{18}$ Our control patients experienced a high index of recurrence or persistence of haemorrhage (57.9\%), confirming the validity of our criteria as unfavourable prognostic indicators. Taking all this into account, we need larger series to confirm wider prognostic clinical parameters. Although the inclusion of more restrictive criteria makes it easier to obtain positive results with smaller samples, it could easily be argued that some patients who did not meet the criteria could have benefited from thrombosclerotic treatment. As can be seen in Table I, only around $16 \%$ of patients with bleeding duodenal ulcer were included in the trial. An apparent additional limitation is that few patients with non-bleeding vessels were included. Most of these patients were not entered because they did not meet the additional clinical criterion concerning transfusion needs. Because our endoscopy unit is available on a 24 hour basis (emergencies are managed by 'on-call' system) our bleeding patients are endoscoped early. This explains why few patients lacked stigmata of bleeding and why most of those with a non-bleeding visible vessel had come to the unit before receiving more than two units of blood. On the other hand, some actively bleeding patients entered in the trial only when a haemorrhagic recurrence had taken place, having been previously endoscoped and not included in the trial because a non-bleeding vessel had been identified and less than three units of blood had been administered at the first endoscopy.

Because local injection techniques have emerged at the same time as thermal haemostasis devices are being accepted more and more, it is mandatory to compare both methods. Thrombosclerosis has the advantage of simplicity and applicability, even in the duodenal cap, but there 
have been very few comparative trials at the present time. Some reports have used absolute ethanol, comparing it with multipolar electrocoagulation, ${ }^{29}{ }^{30}$ without apparent difference, but it should be less effective than heat probe. ${ }^{31} \mathrm{~A}$ single report compares Nd YAG laser, adrenaline, and polidocanol. ${ }^{28}$ Adrenaline plus laser should be as effective as adrenaline plus polidocanol. Obviously, more trials are needed to reach a definite conclusion.

Another topic to be discussed is that related to endoscopic technical aspects. We selected ethanolamine oleate on the basis of our lengthy experience with this agent in sclerotherapy of oesophageal varices. We have been impressed by the rarity of complications, especially stenosis or deep necrotic features. Ethanolamine should induce thrombosis and necrosis phenomena at intra- and perivascular levels. ${ }^{32}$ Thrombin has not been shown to increase the effectiveness of epinephrine in ulcer sclerotherapy, ${ }^{33}$ but we have not found similar studies combining sclerosing agents and thrombin. We have administered large doses of ethanolamine, without apparent necrotic complications clinically or at follow up upper endoscopy on day 7. Obviously, however, we cannot exclude a similar or greater effectiveness of other sclerosing agents or combinations of agents. Only larger series or multicentre trials will be able to answer these questions.

Finally, poor visibility frequently hindered the treatment, as has also been pointed out by others. ${ }^{19}$ Studies on bolus administration of vasoactive drugs may be indicated to circumvent this problem by momentarily lessening the blood flow, in spite of the current poor acceptance of these substances as definitive treatment for gastrointestinal bleeding.

In conclusion, thrombosclerosis does seem to be a useful tool in managing a bleeding duodenal ulcer in selected patients.

1 Fleisher D. Endoscopic therapy of upper gastrointestina bleeding in humans. Gastroenterology 1986; 90:217-34.

2 Moretó M, Zaballa M, Ibáñez S, Setién F, Figa M. Efficacy of monopolar electrocoagulation in the treatment of bleedin gastric ulcer: a controlled trial. Endoscopy 1987; 19: 54-6.

3 Linscheer WG, Fazio TL. Control of upper gastrointestinal hemorrhage by endoscopic spraying of clotting factors. Gastroenterology 1979; 77: 642-6.

4 Fuchs KH, Wirtz HJ, Schaube H, Elfeldt R. Initial experience with thrombin as injection agent for bleeding gastroduodenal lesions. Endoscopy 1986; 18: 146-8.

5 Leung JWC, Chung SCS. Endoscopic injection of adrenalin in bleeding peptic ulcers. Gastrointest Endosc 1987; 33: 73-5.

6 Wördehoff D, Gros H. Endoscopic hemostasis by injectiontherapy in high-risk patients. Endoscopy 1982; 14: 196-9.

7 Sugawa C, Fugita Y, Ykeda T, Walt AG. Endoscopic hemostasis of bleeding of the upper gastrointestinal tract by local injection of $98 \%$ dehydrated ethanol. Surg Gynecol Obstet 1986; 162: 159-63.

8 Panés J, Viver J, Forné M, García-Olivares E, Marco C, Garau $\mathrm{J}$. Controlled trial of endoscopic sclerosis in bleeding peptic ulcers. Lancet 1987; ii: $1292-4$.
9 Balanzó J, Sáinz S, Such J, Espinós JC, Guarner C, Cussó X, et al. Endoscopic hemostasis by local injection of epinephrine and polidocanol in bleeding ulcer: a prospective randomized trial. Endoscopv 1988; 20: 289-91.

10 Kitano S, Iso Y, Koyanagi N, Higashi H, Sugimachi K. Ethanolamine oleate is superior to polidocanol (aetoxy sklerol) for endoscopic injection sclerotherapy of esophageal varices. A prospective randomized trial. Hepatogastroentero$\log y$ 1987; 34: 19-23

11 Jensen DM. Sclerosants for injection sclerosis of esophagea varices. Gastrointest Endosc 1983; 29: 315-7.

12 Sarin SK, Mishra SP, Sachdev GK, Throat V, Dalal L, Broor SL. Ethanolamine oleate versus absolute alcohol as a variceal sclerosant: a prospective, randomized, controlled trial. Am $\mathcal{F}$ Gastroenterol 1988; 83: 526-8.

13 Rutgeerts P, Geboes K, Vantrappen G. Experimental studies of injection therapy for severe nonvariceal bleeding in dogs. Gastroenterology 1989; 97: 610-21.

14 Kitano S, Hashizume M, Yamaga $\mathrm{H}$, Wada $\mathrm{H}$, Iso $\mathrm{Y}$, Iwanaga $\mathrm{T}$, et al. Human thrombin plus 5 per cent ethanolamine oleate injected to sclerose oesophageal varices: a prospective oleate injected to sclerose oesophageal varice
randomized trial. Brf Surg 1989; 76:715-8.

15 Simon R. Confidence intervals for reporting results of clinical trials. Ann Intern Med 1986; 105: 429-35.

16 Johnston JH. Endoscopic risk factors for bleeding peptic ulcers. Gastrointest Endosc 1990; 36: 816-9.

17 Detsky AS, Sackett DL. When was a 'negative' clinical trial big enough? How many patients you needed depends on what you found. Arch Interna Med 1985; 145: 709-12.

18 Silverstein FE, Gilbert DA, Tedesco FJ, Buenger NK, Persing J. The National ASGE survey on upper gastrointestinal bleeding. Gastrointest Endosc 1981; 27:80-93.

19 Brullet E, Campo R, Bedos G, Barcons S, Gubern JM, Bordas $\mathrm{JM}$. Site and size of bleeding peptic ulcer. Is there any relation to the efficacy of hemostatic sclerotherapy? Endorelation to the efficacy
scopy 1991 ; 23: 73-5.

20 Randall GM, Jensen DM, Hirabayashi K, Machicado GI Controlled study of different sclerosing agents for coagulation of canine gut arteries. Gastroenterology 1989; 96: 1274-81.

21 Bouygues M, Ricotier E, Bour B. Traitement endoscopique des hémorragies digestives graves par injection hémostatique. Gastroenterol Clin Biol 1987; 11: 663-7.

22 Di Felice G. Endoscopic injection treatment in patients with shock and gastrointestinal bleeding or stigmata of recent hemorrhage. Endoscopy 1987; 19: 185-9.

23 Sugawa $\mathrm{Ch}$. Injection therapy for the control of bleeding ulcers. Gastrointest Endosc 1990; 36: 850-2.

24 Rutgeerts P, Vantrappen G, Broeckaert L, Coremans G Janssens J, Geboes K. A new and effective technique of YAG laser photocoagulation for severe upper gastrointestinal laser photocoagulation for severe
bleeding. Endoscopy 1984; 16: 115-7.

25 Heldwein W, Lehnert P, Martinoff S, Loeschke K. Local epinephrine injection improves the therapeutic effect of $\mathrm{Nd}-\mathrm{Yag}$ laser treatment of arterial peptic ulcer bleeding. Endoscopy 1988; 20: 2-4.

26 Boix J, Planas R, Humbert P, Fábrega C, Villagrassa $M$ Endoscopic hemostasis by injection therapy and electrohydrocoagulation in high risk patients with active duodenal bleeding ulcer. Endoscopy 1987; 19: 225-7.

27 Swain CP, Storey DW, Bown SG, Heath J, Mills TN, Salmon $\mathrm{PR}$, et al. Nature of the bleeding vessel in recurrently bleeding gastric ulcers. Gastroenterology 1986; 90: 595-608.

28 Rutgeerts P, Vantrappen G, Broeckaert L, Coremans G, Hiele $M$. Comparison of endoscopic polidocanol injection and YAG laser therapy for bleeding peptic ulcers. Lancet 1989; i: YAG laser

29 Woods A, Sanowski RA, Waring JP, Foutch PG. Endoscopic therapy for gastric and duodenal ulcer bleeding: a comparison of BICAP coagulation versus ethanol sclerotherapy. Gastrointest Endosc 1988; 34: 209

30 Laine L. Multipolar electrocoagulation versus injection therapy in the treatment of bleeding peptic ulcers. A prospective randomized trial. Gastroenterology 1990; 99: 1303-6.

31 Jin HJ, Kang WM, Tsai YT, Lee CH. Heat probe thermocoagulation and pure alcohol injection in massive peptic ulcer haemorrhage: a prospective, randomised controlled trial. Gut 1990; 31: 753-7.

32 Evans DMD, Jones DB, Cleary BK, Smith PM. Oesophageal varices treated by sclerotherapy: a histopathological study. vat 1982; 23: 615-20.

33 Balanzó J, Villanueva C, Sáinz S, Espinós JC, Méndez C, Guarner C, et al. Therapy of bleeding peptic ulcer. A prospective randomized trial using epinephrine and thrombin. Endoscopy 1990; 22: 157-9. 